\title{
E-Purchasing \& the Legislations That Must Be Performed
}

\author{
Mohammed Fawwaz Matalka ${ }^{1}$ \\ ${ }^{1}$ Balqa Applied University, University College Irbid, Jordan \\ Correspondence: Mohammed Fawwaz Matalka, Balqa Applied University, University College Irbid, Jordan. \\ E-mail: Mohdmat@hotmail.com
}

Received: February 8, 2013 Accepted: April 19, 2013 Online Published: May 28, 2014

doi:10.5539/jpl.v7n2p133

URL: http://dx.doi.org/10.5539/jpl.v7n2p133

\begin{abstract}
Our research addressed in (e-purchasing and the legislations that must be implemented) to receive to solutions and recommendations about making e- purchasing less available, it means, that legislation must be frame accepted by these behaviors. To enhance into develop and make abundant, and prevent it from making them inhibitor in the face of its development and introducing. The importance of the study appeared in these contracts. Appear in international description in most acts upon the differences, between the ways, of concluding these epurchasing contracts. That is, e-purchasing signed upon international web not belonged to any country, adding this web taking upon all around the world without any exclusion.

What are the ways that make us receive to these aims? That we will study upon depending on the methodology of the research related to comparative analytical study between Jordanian Legislations. Make us far away from details of public descriptions, besides, legislated and theoretical discussing for most of laws and operational basis.

We will manipulate in this study two chapters: the first is: objective problems and the second chapter: available data bases on the web and finally we put recommendations and results specialized in this subject.
\end{abstract}

\section{Introduction}

In the field of willingness law it is contract implement in general, in the case. The two parties agreed to choose one of the laws to perform. Weather in direct or indirect ways, the chosen legislations implement on the contract in all its sides except the shape and habilitation. Because, they are not included in the truth of the contract field, the law that was limited will perform in all general corners in the contract, the conditions of the correctness and proving this contract and the effects related to this contract. The willingness of both sides in the international agreements wider than the local contracts, because willingness in the national law limited in the ordered bases that must not be accepted except on them or opposite to them, adding, they are limited on the explanation bases and distinguished them that they may opposite them.

The most accepted description of the international contract is that the availability of foreign items in the contract, to mean, no shared bases between the two parties of the contract. This led to the freedom in agreement in limiting the legislations of the contract, the location and the lack of agreement and all the corners of the contract, beside, what related to the legislation implementation.(1)

The law of willingness awarded both of the two parties in the contract the freedom of choosing the legislations of the contract wither its national law or any other foreign laws. But, this absolutely will not prevent from clashing. So two logistical theories appeared discussed the in the authority was gained by to restrict the law that must be performed on the contract: the personal theory and the objective one and we will discuss them later:

Personal theory: the contract in this theory legislation relation between its parties builds on their absolute willingness in limiting all its corners and the effects related to them. As, for e- contracts written in internet which signed upon discussions which do for the wishes of the two parties they are looking for, to limit what they wish to limit in the location of the contract until they receive to the legislations that must be performed. That is, the implement of the any law will depend on the willingness of the two parties in limiting the buttons of the contract, beside this law has any legislation power or order on the contract except in the broadens they get by both parties, all of these will be under the conditions of the contract and it will take the shape of the conditioned contract and not independent condition.(2) 
According, we will find this theory related to many results. From the most important of them that both two parties will gain the freedom of contracting in choosing the law that must be implemented, they are able to limit the best law to perform and the effects related to it and get rid of any rule has negative effects on the contract. This theory gained both parties of the contract the absolute freedom in performing the contract in the best ways they may find to find their aims in direct ways.

Objective theory: the followers of this theory (3) accept on making the contract and will not go more than the law and the contract will be under all the rules of the law which was limited by willingness and the law, that must be performed, and willingness limited it, will save in its rule in implement it in all its ways. This theory did not ignore the right of both parties in choosing the suitable legislations but they afraid of the unavailability of legislations bases regular this contract to lead to go out of any restrict law.

The role of the willingness according to this theory in limiting the contract in limit legislation to main center points in the contract in limited country, the residence of the legislation will be under the capability of the court system, which will research for legislation bases adequate for the contract and not get out of the frame of the country the contract implemented on it.(4)

\subsection{The Importance of the Study}

In spite of the previous theories, we will find from the right of the two parties to choose the legislations that must be performed on the e- purchases. This choice still implement to change this to general principle in limiting the legislation, it is the principle of the power of willingness which will get more than any other subject in the condition that it will not reverse any law in any country which the contract centered on it. But, the subject that we must study is identify the criterion related to the ruler in researching about the legislation they must be performed, to appear in the clash on e-purchasing the problem of clashing of the laws in front of the judgment body (the ruler) ad in front of the judge when he needs to implement the legislation rule or to prevent or demanding from one of the parties to make the judge make his judgments.

\subsection{The Problem of the Study}

Most the contracting parties in the field of the agreement on the e- purchasing favor to put special conditions to solve the problems that may appear to prevent losing rights and to make the contract last for the longest period of time. Because, there are some legislations will permit prevented behaves or illegal behaves in other laws. Thus, both of the two contractors to contain the contract the possible solves for some problems that may appear among the contractors.

Some contracts demand from the contractors to draw legislation frame and put the willingness in some shapes. Like official documents and unofficial documents in traditional purchasing contract, as, the e- purchasing contract on the internet. Is it may demand restrict shape for the contract? Or the contract just verbally contracted by voice connecting, or there are some other ways to contract?

\subsection{The Divisions of the Study}

When the shape is available as a base condition in e-purchasing contracts, can we implement on it the same contract legislation? Is there any legislation bases specialized in the shape? To demonstrate and explain the previous questions we will study these subjects as follow:

First Chapter: Objective Problems.

Second Chapter: the shape and data bases available on the web.

\section{First Chapter: Objective Problems}

Acts resulted from the willingness are many and have many types from these are contracts: e- purchasing contract which may be concluded by the individual willingness like whiff, that is all acts which were perfected issued from the willingness of the parties of international relations. But specialized divisions in the specialized International Laws spread among these willingness acts.

When we study special bases in personal monetary and the specialized bases in the location of the contracting, these matters need from us independent study for every corner from the corners of the contract and research about the law that must be performed and discuss the role of willingness. We may find that the acts of gifts and behests are going out our study to willingness of the two parties because these acts issued from individual willingness.

Legislations and Laws (5) proved doing on the law of willingness as a general base in the law frame that must be performed and all its objective conditions related to the contract agreed on the internet. Thus, contracting the 
contract of e-purchasing is available in the availability of its corners, to, result the good effects from this contract after implementing all its corners. If any of the corners were not implemented the contact will not base.

\subsection{First Demand: Agreement}

Agreement is the base in the contract that concluded and was resulted from the agreement of the willingness of the two parties to act legislated effects looking forward it both parties. The condition in this case is that both of the two parties must have all types of capabilities and on the bases limited by the law to limit all sides of capabilities and the minus capability and incapable. So, all countries have special bases in considering capabilities. The Jordanian and Bahraini Legislators limited that every person become in the age of eighteenth will receive the adulthood age. Those make us act on the text which returns capability and civil case in the nationality law for every person from the persons of the contract. This related to normal person, but there normal person in the foreign legislations completed by the implement the laws of the country which was located in it the efficient ad headquarter of the company, that is related from the Jordanian and Bahraini Civil Legislations Texts. (6)

Availability of agreement is one of the bases corners of the contract. It there are no agreement and accept which they prepare for the willingness of the two parties, the contract will not concluded for the prevention of agreement.

Because acceptance is built in its bases on the acts of the person, thus must be in full capability to result correct acts and may not expired, from the most important of these acceptance, the accept will lay on the laws of the two both contractors the agreed implement on him his national Laws and the accepted person will be so. Because every party implement on him his own country law, after limiting the correctness of the agreement that was issued, and that what do in it some legislators. (7)

Other Legislators said to other sides (8) when they say that the legislations must be implemented are the legislations of the place where the contract concluded. Cause contractors know well the place of contracting, as some Arab Legislations and UNISTRAL specialized in e- commerce limited the place of conclude the contract in the cases they are not limited by the parties of the relation in the residence of writing the message as home for contracting the contract thus the National law for this county is the Law that must be implemented. Here we may find the legislator place a solution to resolve contracts which may result from some persons who consider internet web is not sited in any country because the web extended all over the world and does not belong to any country.

Reverse to legislations texts specialized in e-commerce we find that the project put it in the frame of country where the person who sent the message live, and, if there are more than one place in concluding the contract we will depend on the head quarter for the work and put the contract under the laws home of this center to imply national laws on the contract.

On my opinion when the contract did not implied on it for the nationality of the contractors law or the site of signing the contract. In this case agreement will be used for the law of the judge who look in the suit, because, this matter related to one of the reality problems or the idea of agreement on the contract and this is the first conditioning will be transformed to the law of the judge to make him able from limiting the law of the contract and that will rule all the vocabularies of the contract and its components to make him in full sense resulting from the contract all its effects.

If the contradiction about one of the deficits of the willingness i.e. wrong, chatting or tapping and force, all of these will be under the materials of the contract. Because, the willingness of the contractors go forward limiting the law that must be performed so it will be implemented on all the buttons and effects of the contract, so the same, for the site of concluding the contract it will performed on all the phases of contracting from the first step in contracting forward completing all the steps of contracting to make it easier for the parties all the matters and make clear all the legal behaviors from other matters. (9)

As, most contracts, contained buttons specialized in contracting and limiting the law that must be performed on the contract to make it far in discussing in limiting the law that must be performed and make the contract clear in identifying all the vocabularies and from it the law that must be performed.

\subsection{Second Demand: Site and Cause of Contracting}

Any legal act agreed on it will be for a wish that was held and contracts always concluding for the site of the contract, which is make the bounden i.e. the supplier when he do some thing or preventing from doing some deeds and for the site many conditions discussed above in the first chapter. These conditions may expose to glitches and thus any refusing to implement any of these conditions may result from it contradiction, as, the case 
for the site of performing. It is imaginable make upon performing deficit in some conditions of the site. Manipulation of this deficit will restrict from legislation clashes which may face one of the parties. The place may be legal for some countries and illegal in other countries. When, we limiting the law at first we will get rid of problems which may face one of the parties when deficit happen in the contracting relations and when the site is performed. The same for, the law of the contract, the relativity of the law, buttons, effects and the following points of the contract which were agreed on them. (10)

The purpose of them is from the main basic corners in any contract. But, the specialized court interfered for the judge of subject. Because the restricting of its legality or not build upon general system for the country that the contract followed to it. Country will restrict the legal or illegal, as, the opinion of legislators and go forward (11) performing the legislation of the contract on the cause because there is a relation among all the corners of the contract. Or discuss the contract and the cause because the cause will discuss the direct and main purpose that the willingness of the contractors goes forward.

The legality of the cause is shared between the purpose of the contract and the main cause for the contract. Legality will stimulate many legal shapes for the legality in e-purchasing contracts that were concluded by using internet like making digital wallet or e-money which may break the control laws on the monetary exchange in some countries which lead to illegal acts may break the specialized monetary laws in some countries, as, this break of law will lead to restrict its legality directly and clarified the legislation that must be performed and research in all vocabularies to make it suitable with the corners of the contract to produce right contract without any deficits which may lead to the illegality and disjunction of the contract.

In the case of a deficit find in any of the corners of the contract this behavior will lead to disjunction of the contract. But, the reporting of disjunction, how we can restrict it and in any law? Is it the law of the site of the willingness? Or, the law of the shared home is implemented? Or, the place of signing the contract the legal base that obligates some behaviors is the same that restrict the responsibility laid on the contradiction of this behavior. Naturally is that the legislation that must be performed on the contract is must perform on the contract and it will be specialized in the nullification of the contract if any of the corners are left.

If nullification is found because the deficit in the habilitation of any of the contractors of both of them, the personal Legislation will perform for both of the parties. Because, it is the law that must be performed on the habilitation of the contractors, as, the bases of attribution will convert the habilitation to the national laws for both of the contractors, i.e. for the home of every party from the parties of the contract. (12)

If the legislation for the contract is limited It is responsible for limiting the kind of nullification wither it is absolute or relative, who has the right to nullification the contract, the period of the right, the possibility of making the contract nullified and the effects will happen upon the nullification. All the previous problems were limited by the Jordanian and Bahraini Legislators when they refer each of them to nullification and what will happen after that to the legislation of the contract when the contractors agreed on it.

\section{Chapter Two: Available Data Bases on the Internet Web}

Limiting legislations frame that must be performed on the e-purchasing contract go with us to study the surrounding problems which was concluded by using electronic methods as limited by the legislator in the Jordanian e- dealing and commerce law in Bahrain.

From the most important of these the formal problems which may face the contractors when the contract concluded, the same case, in data bases that were available on the internet, when they are not limited in one country but has internationality and not implemented on some countries. This will be treated through two demands as follow:

First demand: formal problems

Second demand: available data bases on internet web

\subsection{First Demand: Formal Shape Problems}

In agreeable contracts, there are some traits to limit formal shape problems and get rid of it, to save on the description of agreement in the contracts. But the project will fulfill it because of some purposes. Formal shape must be available in Jordanian data law and Bahraini Approving Law in some acts in writing between the two parties of the relation in the civil acts that accessed the amount of money restricted in the project as mentioned in the materials specialized in this condition, this will happen in in the deals among normal people and not among merchants. (13) Formal shape is her put for approving the act and not the correctness of it, it may demanded by the legislator to assure the civil rights result upon the act completed. Some legislations specialize in e-commerce 
obligate the availability of some conditions in the contract because it is one of the written documents electronically, to assure from some acts that was completed and the possibility of approving the contract in the future so as to make ever party from getting his right in the way that was written in it in the contract. Oppositely when these conditions are not available will not result in incorrectness of the acts, but, they are only for approving them as was mentioned by the legislator.

Formal shape is a condition must be available for the correctness of the e-contract, As it is in written shape and concluded electronically, to save the information specialized in the contract and retrieve them in any time, to make both parties in the contract to refuse any point in the case of any deficit happened, As, writing one of the ways from locution ways about the willingness of both parties. Some can inter data by using personal computers connected in the web in writing in using keyboard specialized in his machine, by using the scanner or by using any method the person can enter information to the personal computer to send them to both parties. Writing does not take one shape but as usually in any way, so, the legislator did not restrict the way. But, save them responding for all developments, because of these bases of the written documents logarithmic equations the machine fed with them to result the writings we see them on the screen and after pressing the buttons of the key board.

Avoidance of the act that was completed in a limit formal shape is considered one of the most important of the corners of the contract. If the avoidance deleted that will lead to break the contract and The sites that presented in it used in approving the contract through clarifying the shape that put in it the contract wither it is verbal or in written shape and the shape that the contract was written in it, thus, all of these under the law implementation that follow to the contract wither the condition in whole or objective. (14)

In spite of, the formal shape stated in disappearing, but, there are some contracts depended on special formal shape, when we implement the formal shape and become the base for the reference of the legislation that must be performed in the case the contract depend limit shape in itself. The general base put the contract under the legislation of the site of its signing, so, this base is not order but it may be chosen, as, mentioned in the material (20/1) from the Jordanian Civil Law which agreed that the two parties of the contract have the choice to choose the law which were ruled under it the shape of the contract or the site of writing the contract.

The base of the freedom of the choice must be implemented on the formal shape conditions that were produced upon the willingness, specially, the authority of the willingness which has the most important base in the field of contracts and the principle of the authority of willingness will activate when the field is opened for the two parties of the contract in choosing the legislation that regularize the formal shape as the case for the objective conditions.

Purpose form put the contract under the legislations on the site where it was written make it easier for both of the contractors to choose the law of the willingness wither it is the home law or any other law was agreed on it between the two parties of the contract. The base form this act make the willingness of the two parties reality and availability of clarification on the contract beside be far away from vague by giving both of them the freedom in willingness in the law that must be performed on the formal shape conditions.

We can say that the legislations must be performed on the formal shape conditions are the same legislations that get objective conditions under it. Because, the base of subject: refers to the authority of the willingness by both contractors, who limited the law of the contract which is adequate with the rules of the contract.

\subsection{Second Demand: Available Data Bases on the Internet Web}

We can find available data on internet any time all over the world without any borders, to mean, it is not any information, but, links among countries, governments, organizations and establishments in the private sector, so, these information can expose to offensive any time and break it to collapse these information finally, so, we must search about the law that must be implemented on these data, that we will try to shed light on by collecting data and export them as follow:

Referring to Civil Jordanian Law we can find that it refer the Law must be performed on the harm acts to the country in which the act was completed. (15) but the court go forward to perform the local legislations on uncontracting acts and available in it foreign element, because, referring what they must do and not mentioned in the contract to the national Law is the solution to the shapes of conflicting in this conflict (16).

National legislations implementing demanding the sum of the site and the judge who will introduce the solution for the conflict on the legislations of the site, but, if it is illegal upon one party and by the opinion of the judge legal here the responsibility will not found because the law of the judge must perform. 
Assurance the demands of both parties is the social aim from the Law. It will restrict what is legal or illegal must not act, because it will result in harm for one of the parties, if the matter here disabled. Thus the responsible person will be under implementing the materials of the law and must pay compensation because of harm happened upon him because of his breaking the law when he left the Law behind him. The law of the site is specialized because it was opposite resulting upon his disobedience for the bases of the law that must be performed. The legislations of site will be performed whatever the nationality or the place of the person who is responsible about the harm. Or the wronged as the harm related to the site as a result is more useful implement the Law of the Site. (17)

Dominant of the Government principle on its county include using the responsibility upon harm full acts which were completed in county frame to the government law, because, the harmful act was completed on its land, beside the behavior bases for the compensated principle must fooled by performing the law of the site which was completed in it the acts that adherence. As, a result of his law the act was considered illegal but it will not in any place legal. (18)

Performing local laws does not stimulate any difficulties in the cases of the harmful act in the same county frame in the government which it belonged to as the harm happened in more than one country as happened in internet web, through it we can observe any e-site and reciprocation of data through any country. Thus, what is the Law that must be performed on this harm? That it go out all the borders of the countries.

\section{Availability of Data Bases and Manipulating Them in the Same Country}

Some said, in restricting the legislations that must be performed when the responsibility happened as a result of harmful act on the data bases in more than one country, the law of the country that was happened in it the harm. Because the law of the land restricted that this act is harmful deed and resulting upon it Legal Responsibility that is shortened responsibility, as, its rules aims to protect the community from illegal acts. The site of the harmful act is the legal frame that must be performed because harm acts happened in this place and was considered as that depending on legal bases for this county. Interpretation of this, the site of the illegal act is the right criteria upon it we can restrict the acts resulted upon the illegal deeds. That is what duplicates with available databases on the internet which can be reciprocated through more than one county.

Other opinion used to put this act under the country which live in $t$ the person who was harmed wither he is normal person or honorably: the base is exposing his own privet data and make harm for them. In this case, the law of the country for the person whom was harmed - owner of the data- must be performed on this harm act which broke the borders and happened in more than one country.

There are many problems facing performing this kind of legislations because the other party demands will expose to instability and oscillations. It will be source of important and this kind of legislations will not perform the person whom harmed demands.

All of these appeared upon it other opinion take in the law of the harm behavior, because, harm is the first condition for demanding responsibility beside the owner of the suit have not the right in the suit but if he had harm and harm did not fixed here there is no responsibility. Time of harmful begin in it the period of prescription about the responsibility and vice versa. The volume of the harm took into account in estimating the compensating because it is the base for limiting the compensating. (20)

As mentioned previously, we can conclude that the opinion performed the location of harm as it's the home of the harm. National legislations for this person is performed on the harm acts, as, it will imply the social equity beside the elements of responsibility will focus on are here. As, this act may be legal in other legislations. The person whom treated with the data bases in internet web know well the provider of the data and the country where he live so the data will be located under the performing of the location of the person (21)

\section{Closure}

The frame of performing legislations on e-purchasing is study considered from the subjects of present time which still under debate and research. There are less researchers studying in this subject. As we can say, that this subject has not its right in discussing and study. Many studies about it and they are rare and lockage of studies because of the modernity of the subject and un clarifying its vocabularies which they are in developing daily and continuously.

Researcher tries in this study discussing this subject to clarify the legislations that must be performed on e-purchasing to understand well in discussing the opinions of legislators to receive to new vision about all these subjects. As may I added some simple information on this subject may it stand as support for the researchers and demanding this kind of contracts. 
After the research was completed in this subject in most of its elements and mostly clarified all the sides of it. Researcher must detail what he received from results in this research, after locating the recommendations and special suggestions in this subject.

\section{Results}

Depending on our previous study it is clear from discussing the opinions of legislators in law summarized the following results:

- Willingness of both contractors will limit the legislations that must be performed on e-purchasing which concluded on internet, this by the opinion of all legislators,

- In the case of agreement, the agreement will be under the law of both contractors but must be implemented for the national law and that will be referred to agreement of both contractors because every party will implement on him his national law as the agreement will be limited the correctness of agreement that was issued, and that what said on it many legislators.

- Legislator opinion to put the contract under to county law for the place of sender and that is the site where the contract concluded, so the contract will be under these legislation bases for the home country. In the cases there are more than one work place the judge will credit the head courtier for the work and site the contract under the nationality of this center and national law will implemented on the contract.

- Purpose from site the contract under the legislations of its concluded is to make it easier for both contractors in choosing the law of the contract. Wither, it is the national law or any other law which was greed on it between the two contractors. Bases from this behavior is achieve the aims of both parties of the contract and use clarity in the contract to keep far away from unknown in demanding freedom for both parties for the legislations must be performed on the shaped condition's.

- Performing local laws did not stimulate any difficulties in the case the harm act was happened in the same frame of the county in the country in which the harm was happened.. In the cases the harm was happened in more than one country as happened in internet web which through it you can watch any electronic site and receiving information in any country in the world.

\section{Recommendations}

- Researcher hopes that the law must be performed on shaping conditions is the same law that the objective conditions had. Because the bases of put the contract under any law refer to the willingness of contractors who can only limit the law of the contract adequate with the rules of the contract.

- Taking into account the place of the harm which in the nationality of the person whom was harmed, because the national will implement on this harm act. As it responsible for social equity and centered on it the elements of responsibility. This act may be legal in other legislations,

- The person who is treating data bases must be on the internet web and he have to know the supplier of information beside the home of these suppliers so data will be under the national law of his settlement

\section{Remarks}

(1) Dr. jaber jad abddarhman: third Arab international specialized law in clashing laws, al alalmea printing, Cairo (1962). pp. (58 and after).

(2) Dr. Ezz Elden abdallah: special international law, al-Arabia Renaissance House. Cairo (1974), p. (392).

dr. mohmoud mohammad yaqout: freedom of contractors in choosing the law of the international contract between theory and practicing comparative analyzed study in the light of new dimensions, Knowledge facility, Alexandria (2000), p. (99).

dr. nermeen mohammad mahmoud soboh: the principle of the contract is the approach of contractors and the limited were performed on it in the international trading, al-Arabia Renaissance House. Cairo (2002), pp. (79 and after).

(3) Dr. mohmoud mohammad yaqout: the same previous reference, pp. (95 and after), dr. hisham ali sadeq: the legislations that must be performed on international trading, University Thought House. Alexandria (2001)., pp. (282 and after)

(4) Dr. mahmoud mohammad yaqout: the same previous reference, p. (97). Dr. nermeen mohammad mahmoud soboh: the same previous reference, pp. (81-84).

(5) For more : 
Dr. jad abddarhman: the same previous reference, p. (54 and after).

Dr. samea rashid: role of material (24) civil in solve laws clashing problems: future theory, unpublished pp. (12 and after).

Dr. hisham ali sadeq: the same previous reference, p. (125 and after) Dr. nermeen mohammad mahmoud soboh: the same previous reference, pp. (73-85).

(6) material (12) from the civil Jordanian law"1- occur on the civil case for persons was prepared the law of the country whom belong to it in their nationality, as, in financial acts which contracted in Jordanian law and responding in effects on it, if any of the parties foreigner without complete nationality and the un complete nationality refer to reason was hidden the second party cannot know it, this reason will not effect on the role in the nationality, 2- but the legal system for the persons whom have foreign nationality like companies, communities and establishments and others, here will perform on it the law of the country in which these person there head quarter company if they directed their activities in the Hashemite kingdom of Jordan here the Jordanian law will be performed". Material (civil bahraini law) (except what mentioned din the text in the civil commercial procedures laws, will be in law special in the la what must be performed on the elements contained foreign element and clashing on it the laws).

(7) dr. ahmed abed al-karee salameh: the science of base of clashing and choosing among laws, al-Arabia Renaissance House. Cairo (1996) buttons (608).

(8) dr, hamed zaki: special international Egyptian, without publisher (1940), p. (348).

Dr. sami bade;i mansour: moderate in special international law, al-Arabia Science Foundation Publishing, Beirut (1994), pp. (490 and after).

Dr. fuad riyad \& dr, samya rashid: judgments international trading. House of Culture for publishing and distributing, Amman (1998). p. (167).

Dr. memdouh abed alkareem armoush: special international Jordanian comparative law, House of Culture for publishing and distributing, Amman (1998) p (167).

Dr. hisham ali sadeq: the same previous reference, pp. (670 and after)

(9) Dr. sami bade;i mansour: the same previous reference, p. (491).

Dr. mamdouh abed al -kareem al-omoush: the same previous reference, $p$ (671).

Dr. ahmed abed al-karee salameh: the law of international; contract, al-Arabia Renaissance House. Cairo (2001), pp. (220 and after).

(10) Dr. hamed zaki: the same previous reference, $p$ (345).

Dr. ahmed abed al-karee salameh: the law of international contract, the same previous reference, p.(223).

(11) Dr. hamed zaki: the same previous reference, $p$ (346).

Dr. hamed zaki: the same previous reference, $\mathrm{p}$ (346), dr. ahmed abed al-karee salameh: the law of international contract pp. (223-224).

(12) Dr. ahmed abed al-karee salameh: the law of international contract, the same previous reference p. (25).

(13) From the following texts we can find that the legislator demanded the condition of writing if the amount of money exceeded money, according the components of the text that demanded writing and not recommended in witness if the amount of money exceeded the limit. Material (28/1/a) from the Jordanian proving law:" if the contracting money in other than the commercial materials exceeded than one hundred JOD or not limited in amount here the witness is not accepted in proving the point or not other than there is agreement to text have judgment in this matter". Material (61) from Bahraini proving Law " in other than commercial materials if the legal amount money exceeded than the value of legal amount more than twenty dinars or the amount is not limited here the wetness of witnesses in proving it or getting rid of it unless there are written document unless there is agreement or text said other ways. Here the amount of money accepted in its value $n$ the time of act here we can proving in the witness of witnesses if the amount of money more than twenty dinars not gained except in including the original. If the suite contain many demands constructed from many resources here we can prove in witness of witnesses in every demand has not a value more than twenty Dinars even if these demands in sum more than this value wither it is construct from the relations among the opponents themselves or behaviors from one nature. Here the result in paying the money if it is partial from the original value." 
(14) Dr. ahmed abed al-karee salameh: the law of international contract, the same previous reference pp. (360-366)

(15) Material (22) from the Jordanian Civil Law "1- on the subcontract subjects will be implemented the law of the country on which the act was happened which construct the act 2- previous material will be excluded in construct subjects from the harm act on the events outside and legal inside the Hashemite Kingdom of Jordan even it is illegal in the country the harm happened in it,"

(16) Dr, adel abu hashem hoteh: electronic information contracts services in the especial international law, al-Arabia Renaissance House. Cairo (2004), pp. (242- 243(.

(17) Dr. jaber jad abddarhman: clashing of laws, alalemia Printing press, Cairo (1996), pp. (474-475)

(18) Dr. hisham ali sadeq: clashing of laws in the responsibility of infects problems according to sea clashing and accidents happened on the deck of ships in the light of general principles and the rule of Brussels agreement in 1910. Knowledge facility, Alexandria, without publishing year, pp. (15 and after)

(19) Dr. ezz al deen abdalh: the same previous reference p. (518)

Dr. fuad riyad \& dr, samya rashid: the same previous reference p. (325).

(20) Dr. ahmed abed al-karee salameh: the same previous reference p. (1199).

Dr. fuad riyad \& Dr. samya rashid: the same previous reference p. (236).

Dr. husam aldeen fathi wasef: demanded elasticity in implementing the national law on the contracted infects responsibility events, without publishing year and without publisher. pp. (68 and after).

(21) Dr. hisham ali sadeq: clashing of laws in deficit responsibility problems, the same previous reference $\mathrm{p}$. (27).

Dr. adel abu hashem hoteh: the same previous reference pp. (249-250).

\section{References}

Abdallah, E. A. (1974). Special international law. Cairo: Al-Arabia Renaissance House.

Abddarhman, J. J. (1962). Third Arab international specialized law in clashing laws. Cairo: Alalemia Painting al.

Abddarhman, J. J. (1996). Elashing of laws. Cairo: Alalemia Painting.

Alahwani, H. A. (2000). The general theory of adherence (1st part). Cairo: Al-Arabia Renaissance House.

Al-dawoodi, G. (1965). Theory of deferring in the special international law. Baghdad: Modern Printing House.

Al-hdawi, H. (1997). Special internationally win clashing laws. Amman: House of Culture for Publishing and Distribution.

Armoush, M. A. A. (1998). Special international jordanain comparative law (p. 167). Amman: Library House of Culture for Publishing and Distribution.

Fahmi, M. K. (1980). Origin of special international law (2nd ed.).

Hoteh, A. A. H. (2004). Electronic information contracts services in the especial international law. Cairo: Al-Arabia Renaissance House.

Ibrahim, A. I. (1997). Special international judgment. Cairo: Al-Arabia Renaissance House.

Mansour, S. B. (1994). Moderate in special international law. Beirut: al-Arabia Science Foundation Publishing.

Rashid, S. (n. d.). Role of material (24) civil in solve laws clashing problems: future theory (Unpublished, pp. 12-after).

Riyad, F., \& Rashid, S. (1997). Origins of law clashing. Cairo: Al- Renaissance House.

Sadeq, H. A. (1974). Clashing of laws, comparative study in the general principles and solutions were decide in Egyptian legislations. Alexandria: Knowledge facility.

Sadeq, H. A. (n. d.). Clashing of laws in the -responsibility of infects problems according to sea clashing and accidents happened on the deck of ships in the light of general principles and the rule of Brussels agreement in 1910. Alexandria: Knowledge facility.

Salameh, A. A. A. (1996). The science of base of clashing and choosing among laws. Cairo: Al-Arabia Renaissance House. 
Salameh, A. A. A. (2000). Environmental tourism electronic special international law. Cairo: Al-Arabia Renaissance House.

Salameh, A. A. A. (2001). International contract law. Cairo: Al-Arabia Renaissance House.

Sami, F. M. (2006). International commercial judgments. Amman: House of Culture for Publishing and Distribution.

Soboh, N. M. M. (2002). The principle of the contract is the appraoch of contractors and the limite were performed on it in the international trading. Cairo: Al-Arabia Renaissance House.

Wasif, H. A. F. (n. d.). Demanded elasticity in implementing the national law on the contracted infects responsibility events.

Yaqout, M. M. (2000). Freedom of contractors in choosing the law of the international contract between theory and practicing comparative analyzed study in the light of new dimensions. Alexandria: Knowledge facility.

Zaki, H. (1940). Special international Egyptian.

\section{Copyrights}

Copyright for this article is retained by the author(s), with first publication rights granted to the journal.

This is an open-access article distributed under the terms and conditions of the Creative Commons Attribution license (http://creativecommons.org/licenses/by/3.0/). 